\title{
Amores glocales, noviazgos transnacionales. La búsqueda virtual de pareja mixta por parte de hombres españoles
}

\section{Glocal loves, transnational dating. The virtual search for a mixed partner by spanish men}

\author{
Jordi ROCA GIRONA \\ Departamento de Antropología, Filosofía y Trabajo Social. Universidad Rovira i Virgili \\ jordi.roca@urv.cat
}

Recibido: 10 de enero de 2011

Aceptado: 21 de febrero de 2011

\begin{abstract}
Resumen
El artículo aborda el fenómeno reciente y creciente de las parejas mixtas heterosexuales entre un hombre español y una mujer extranjera. Dentro de la variedad de cuestiones que en la literatura académica internacional han empezado a tratarse en relación al tema, tales como las motivaciones presentes en la decisión de búsqueda de una pareja de esta naturaleza o los amplios procesos de negociación a los que debe enfrentarse tanto en el ámbito privado como en el público, nuestra aportación se centra en uno de los aspectos fundamentales de la realidad de buena parte de las uniones mixtas: la búsqueda virtual de una pareja transnacional a través de redes románticas y agencias matrimoniales especializadas presentes en Internet y el noviazgo posterior en este mismo entorno virtual. Se discuten, al efecto, cuestiones como la de la mercantilización de la intimidad y la de las novedades y continuidades que presentan los amores del ciberespacio en relación a los noviazgos convencionales.
\end{abstract}

Palabras clave: Parejas mixtas; ciberamor; mercantilización de la intimidad, noviazgos transnacionales, relaciones amorosas online.

\begin{abstract}
This paper deals with the recent and growing phenomenon of heterosexual mixed couples between a Spanish man and a foreign woman. Many topics have been covered by the international scholarly literature, such as the motivations leading to the decision of searching for a couple of these characteristics, or the varied processes of negotiation encountered in the public and private space. Our contribution is based on one of the fundamental aspects of the reality of and important number of mixed couples: the virtual search for a transnational couple through romantic websites and specialized marriage agencies on the Internet, and the subsequent dating period on the virtual space. We discuss topics such as the commodification of intimacy and the novelties and continuities of loves in the cyberspace in relation to conventional dating.
\end{abstract}

Keywords: Mixed couples, cyberlove, commodification of intimacy, transnational dating, online love relationships. 
Referencia normalizada: Roca Girona, J. (2011). Amores glocales, noviazgos transnacionales. La búsqueda virtual de pareja mixta por parte de hombres españoles. Revista de Antropología Social, 20, 263-292.

SUMARIO: 1. Introducción. Los matrimonios mixtos: entre lo global y lo local. 2. Metodología: una etnografía virtual y multisituada. 3. Parejas mixtas, supermercado matrimonial y ciberamor: las rutas globales de búsqueda de cónyuge. 4. La búsqueda virtual de amor transnacional. 4. 1. Redes románticas. 4. 2. Agencias matrimoniales. 5. Conclusiones. 6. Referencias bibliográficas.

\section{Introducción. Los matrimonios mixtos: entre lo global y lo local}

En 1996 se realizaron en España apenas 8.000 matrimonios mixtos o binacionales, esto es: uniones heterosexuales entre un cónyuge español y otro extranjero. Algo más de una década después, en 2009, esta cifra se había elevado a casi 30.000. De estas uniones, algo más de 17.000 correspondían a matrimonios entre un hombre español y una mujer extranjera, y cerca de 12.000 a bodas entre mujeres españolas y hombres extranjeros. Para el conjunto del período comprendido entres estos dos años — 1996-2009 — la proporción es similar: 151.190 hombres españoles se casaron con una mujer extranjera frente a las 103.440 mujeres españolas que hicieron lo propio con un hombre extranjero (Fuente: INE, elaboración propia) ${ }^{1}$. Esta progresión y distribución de las cifras coincide en gran medida con lo sucedido durante este mismo período aproximadamente en algunos de los llamados países ricos del occidente europeo, donde una parte de su población masculina, en mucha mayor medida que la femenina, comenzó a elegir pareja sentimental entre mujeres de algunos países pertenecientes a regiones del Caribe, Latinoamérica, el este de Europa y el sudeste asiático.

La eclosión y el crecimiento de los noviazgos y matrimonios transnacionales deben ser ubicados, pues, en la década de los noventa del siglo pasado, con la aparición de portales y agencias especializadas en internet ${ }^{2}$. En Estados Unidos, por ejemplo, el lugar en donde el fenómeno alcanza una mayor dimensión desde la perspectiva de la "importación de esposas", en los años noventa se constata una creciente presencia de mujeres filipinas — que ya en la década de los 80 habían destacado por sus matrimonios transnacionales con hombres principalmente australianos - en las agencias matrimoniales, seguidas por las mujeres de Europa del Este y de la ex Unión Soviética (Constable, 2003). De hecho, y respecto a las mujeresnovias, el Informe sobre el estado de la población mundial del Fondo de Población de la Organización de las Naciones Unidas (UNFPA) de 2006, entre los muchos

${ }^{1}$ Sin embargo, hay que señalar que hasta el año 1999 los hombres no toman la delantera a las mujeres españolas en uniones matrimoniales con un cónyuge extranjero.

${ }^{2}$ Hay que señalar, no obstante, que los datos estadísticos correspondientes a uniones mixtas no distinguen - al menos en España - entre las parejas que son consecuencia de la emigración —es decir, que se conocieron en el país de destino del cónyuge emigrante- y las que son causa de la emigración - aquellas en las que uno de los cónyuges emigra como consecuencia de la búsqueda y del encuentro transnacional de pareja-, que es el colectivo que nos va a interesar en este artículo. 
datos que aporta recalca un aumento importante de mujeres que migran mediante una relación matrimonial. Esto es especialmente destacable, por ejemplo, en China y en otros países asiáticos en general. No en vano se trata de un lugar preferente de búsqueda de esposas por parte de hombres estadounidenses, de donde salen al año unas 300 mil mujeres-novias; siendo así que se subraya también el caso de Rusia, de donde emigran con este propósito entre 10 y 15 mil mujeres anualmente y donde existe también una importante y densa red de agencias de intermediación que se dedican al negocio de la formación de parejas.

La contextualización de este fenómeno reciente y en aumento de las uniones mixtas pasa, a nuestro entender, por la consideración de un conjunto de factores tanto de carácter material como ideológico que poseen una dimensión global y una expresión local. El marco supranacional, en este sentido, estaría caracterizado por la creciente existencia de flujos transnacionales y realidades de carácter globalizado, por la emergencia y extensión de las nuevas tecnologías de la información y la comunicación (TIC) y por el paso de una sociedad centrada en la producción a otra centrada en el consumo y en la elección. Esto nos sitúa en un escenario en donde los límites y las fronteras entre migración y movilidad se difuminan al tiempo que crece su intensidad en relación a recursos de toda índole: personas, capitales, mercancías (Appadurai, 2001; Featherstone, 1990; Hannerz, 1998; Robertson, 1992). La movilidad electrónica característica de la sociedad de la información hace posible que cualquier lugar del mundo sea susceptible de estar cerca o de ser accesible con carácter inmediato. Estas tecnologías, además, favorecen la existencia de la llamada sociedad de consumo o, mejor, de consumidores (Featherstone, 1991; García Canclini, 1995), en el marco de lo que ha venido denominándose sociedad electiva (Beck, Giddens y Lash, 1994; Chalvon-Demersay, 1996; Giddens, 2000): cada vez tenemos y queremos tener a disposición un mayor número de opciones posibles ante cualquier circunstancia de nuestra vida y el mundo relacional se ve también determinado por esta oferta/necesidad de ampliar nuestro potencial de elección, que ya no tiene por qué limitarse al entorno cercano de sociabilidad.

El territorio amoroso tampoco restará inmune a estos cambios, siendo así que el patrón amoroso romántico que vinculó al matrimonio la pasión y la durabilidad será sustituido, en opinión de Giddens (2000), por el de amor confluente: un amor contingente, activo, que se desembaraza de la eternidad - "para siempre"- y la exclusividad - "uno y solamente uno"- propias del amor romántico para fundarse en la reflexividad: las relaciones continúan porque así lo eligen ambos miembros de la pareja.

La concreción de este fenómeno global al contexto específico español introduce algunas particularidades que deben ser destacadas. Por una parte, está el reciente protagonismo de España como receptor de migrantes - a diferencia de la mayoría de países en los que se ha producido este fenómeno-, que en los últimos años le ha convertido en el país de la Unión Europea con un mayor número de matrimonios mixtos y de incorporación de población inmigrada. España es el país de la Unión Europea que ha experimentado el mayor incremento de inmigración ininterrumpidamente desde 1997, recibiendo en el año 2006 casi el 45\% de toda la población 
inmigrante que llegó a la U.E., situándose sólo por detrás de Estados Unidos en flujos migratorios a nivel mundial (Rodríguez, 2007).

Por otra parte, España se ha significado también como uno de los países en donde se ha producido una notable transformación en el sistema de género en las últimas décadas, con cambios sociológicos de cierta consideración -incorporación de la mujer a los niveles superiores de formación y al mercado de trabajo y mayor capacidad de control y emancipación de su papel como reproductora- y políticas de género, especial y fundamentalmente legislativas, a menudo de carácter pionero y muy publicitadas tanto dentro como fuera de sus fronteras - matrimonio homosexual, leyes recientes del aborto y divorcio que amplían supuestos y agilizan procesos- . Este extremo, precisamente, alimentó una de nuestras hipótesis de partida, centrada en el hecho de que la mayor independencia material y sentimental, adquirida por las mujeres españolas como consecuencia de los cambios señalados, estaría ocasionando como resultado la resistencia de algunos hombres que, en desacuerdo con este nuevo y cada vez más generalizado modelo femenino, se habrían lanzado a buscar pareja en un mercado matrimonial distinto al del propio país, en el marco de lo que ha venido a denominarse en los últimos años "crisis de la masculinidad"

Nuestra mirada, que se basa en sendos proyectos de investigación ${ }^{4}$, parte de la convicción, por tanto, de la necesidad de articular las experiencias personales y las trayectorias de vida con los factores infra y supra estructurales que hacen posible, producen y/o condicionan las relaciones amorosas entre hombres españoles y mujeres extranjeras, principalmente latinoamericanas y eslavas 5 . Nuestro intento, en fin, como se dijo, huye de la ruptura entre lo global y lo local o de la consideración de una sola de ambas dimensiones, porque, como se ha señalado, todavía tiene sentido la ubicación geográfica tradicional a la hora de sentarse frente al ordenador (Appadurai, 2001: 14).

\footnotetext{
${ }^{3}$ Véase, con carácter general, MacInnes, 1998; Mac an Ghaill, 1996; y Seidler, 2006; y para el caso español Gil Calvo, 1997.

${ }^{4}$ Los datos de este artículo provienen del Proyecto "Amor importado, migrantes por amor: la constitución de parejas entre españoles y mujeres de América latina y de Europa del Este en el marco de la transformación actual del sistema de género en España"; Proyectos de Investigación Científica y Desarrollo Tecnológico; Programa: Acción Estratégica sobre Fomento de Igualdad de Oportunidades entre mujeres y hombres; Plan Nacional de I + D + I (2004-2007), Ministerio de Trabajo y Asuntos Sociales, Instituto de la Mujer (Exp. No 47/05, AMIM, 2006-2008). Formaron parte activa del mismo: Lídia Martínez, Yolanda Bodoque, Montserrat Soronellas y Marija Djurdjevich. En estos momentos hemos iniciado otro proyecto como continuación y ampliación del anterior: "Amores transnacionales: constitución y desarrollo de parejas mixtas en España”. Plan Nacional de I+D+I (2008-2011), Ministerio de Ciencia e Innovación (CSO2009-10187).

${ }^{5}$ Dos de cada tres matrimonios entre hombre español y mujer extranjera es con una mujer americana. Los matrimonios con mujeres europeas se sitúan en segundo lugar, representando alrededor de un tercio de los anteriores. En términos de representatividad estadística, el perfil de unión mixta mayoritaria en España es el de hombre español y mujer brasileña y hombre español y mujer rusa. Para un tratamiento más amplio y profundo sobre la distribución geográfica de los matrimonios mixtos españoles, véase Roca et al, 2009 y Roca, 2009.
} 


\section{Metodología: una etnografía virtual y multisituada}

La naturaleza de las cuestiones que deseamos abordar, más dirigidas a ilustrar la humanidad y la textura de las vidas que a objetivar los hechos y cuantificar los datos, aconsejan la adopción de una perspectiva cualitativa tanto de obtención como de análisis de unas informaciones de naturaleza fundamentalmente descriptiva.

A lo largo del año 2007 se realizaron un total de 65 entrevistas en profundidad, principalmente a miembros de parejas mixtas heterosexuales formadas por hombre español y mujer extranjera, con un total de 71 informantes - hubo 6 entrevistas de carácter doble, a ambos miembros de la pareja a la vez, siendo el resto de carácter individual - , fundamentalmente hombres españoles y mujeres eslavas y latinoamericanas. Debe señalarse que algunos hombres españoles, especialmente, mostraron recelo y declinaron la invitación a ser entrevistados por la imagen negativa que perciben sobre ellos en la opinión pública y los medios de comunicación, impidiendo asimismo a sus esposas contactar con nosotros ${ }^{6}$. Las entrevistas fueron casi todas cara a cara, excepto dos que se han realizado por chat y correo electrónico y por teléfono. En tres entrevistas, con mujeres ucranianas, se precisó traductor. Estas tres entrevistas, junto a otras 12 más, se llevaron a cabo en Kiev en junio de 2007, en el marco de una breve estancia de campo para la observación participante de uno de los numerosos viajes organizados por diversas agencias matrimoniales especializadas. En nuestra incursión en la red, el desvelamiento de nuestra identidad como investigadores en algunos de los chats produjo reacciones opuestas de simpatía, curiosidad y colaboración, incluso entusiastas, y de rechazo y hostilidad, generándose en algún momento, asimismo, un conflicto entre los mismos participantes sobre nuestra presencia.

En cierto modo, pues, la nuestra ha sido una etnografía multisituada (Marcus, 1995) y también una etnografía virtual (Hine, 2004), por cuanto hemos tomado el espacio virtual como una unidad de observación más, aunque no como una unidad de análisis preferente.

Nuestro trabajo, en cierto modo, describe una comunidad global de mujeres y hombres envueltos en relaciones de noviazgo y matrimonio y plantea la cuestión, que no vamos a poder abordar, de cómo el desarrollo de Internet y de las distintas formas de comunicación electrónica han permitido la emergencia de nuevos tipos de comunidades imaginadas (Anderson, 1983; Appadurai, 2001) y cómo los antropólogos pueden acometer el estudio de éstas?

${ }^{6}$ Sabemos de alguna que, no obstante, accedió a hablar con nosotros sin consentimiento de su pareja. En algunos casos la solución consistió en admitir la entrevista sólo con la presencia de ambos cónyuges.

${ }^{7}$ Empezamos a contar ya con un buen número de trabajos que muestran, entre otras cosas, que estas comunidades son complejas, organizadas y dignas de estudio. Sólo a título de ejemplo, pueden verse: Ardèvol et al., 2003; Hine, 2004; Jacobson, 1996, 1999; Miller y Slater, 2000; Mayans, 2002; Rheingold, 1996. 


\section{Parejas mixtas, supermercado matrimonial y ciberamor: las rutas globa- les de búsqueda de cónyuge}

La literatura existente sobre uniones mixtas se integra en el creciente interés científico sobre cómo las relaciones sociales se han tornado cada vez más dispersas geográficamente, impersonales, mediatizadas por, e implicadas en, amplios procesos político-económicos o capitalistas, así como en la atención académica cada vez mayor a la intensificación y compleja interconectividad de los procesos locales y globales. Más específicamente se constata un predominio de trabajos que se centran en los principales itinerarios que recogen los flujos de cónyuges y parejas, así como la dirección y el sentido de los mismos (entre otros, Bermúdez, 2007; Cahill, 1990; Chin, 1994; Cohen, 1986; Cooke, 1986; Halualani, 1995; Mainardi, 2006; Melo, 2000; Riaño, 2003; Robinson, 1996; Suzuki, 2003). También contamos con trabajos de carácter más general que abordan el fenómeno desde diversas perspectivas, describiendo los diversos patrones de género vinculados a la movilidad marital en un contexto global, mostrando a mujeres y hombres que toman la iniciativa, que realizan elecciones y que devienen agentes activos, apuntando las motivaciones y razones para la salida, así como la incidencia de estas uniones sobre el concepto de amor (Acholes, 1999; Barbara, 1985; Clark, 2001; Constable, 1998, 2003; Delcroix y Guyaux, 1992; Gamburd, 2000; Ordóñez, 1997; Parreñas, 2005; Riaño y Baghdadi, 2007; Roca et al., 2009; Simona, 1999). Las investigaciones recientes han hecho hincapié, igualmente, en los nuevos patrones de mercantilización y el crecimiento de los negocios vinculados a la búsqueda de pareja transnacional, en lo que bien podríamos denominar un "supermercado matrimonial global" (Constable 1998, 2003; Heino, Ellison y Gibbs, 2010; Johnson 2007; Johnson-Hanks 2007; Piper \& Roces 2003; Thai, 2008; Wang \& Chang 2002). Más específicamente, los denominados cyberromances y el desarrollo de las relaciones románticas en línea se han constituido en una importante área de estudio, con un cuerpo de literatura creciente (por ejemplo, Baker, 2002, 2005; Donn y Sherman, 2002; Doring, 2002; Hardey, 2002). Dentro de esta perspectiva, se ha documentado por diversos autores (Beck y Beck-Gernsheim, 1998; Shumway, 2003; Zelizer, 2005) que muchos aspectos de la intimidad y las relaciones personales han ido comercializándose cada vez más explícitamente vinculados a los procesos globales de mercantilización. En términos marxistas la mercantilización hace referencia a los procesos de asignación de valor a bienes o servicios que previamente se encontraban fuera del mercado. En este sentido, como ha señalado Constable (2009: 50), la intimidad o las relaciones íntimas pueden ser tratadas, comprendidas o pensadas como si hubieran entrado a formar parte del mercado y, en consecuencia, hubieran pasado a ser susceptibles de ser compradas o vendidas; empaquetadas y publicitadas; objeto de fetichismo, comercializadas u objetivadas; consumidas o con un precio o valor asignados; y vinculadas en muchos casos a la movilidad transnacional y los procesos migratorios, formando parte del flujo capitalista global de mercancías. La metáfora del mercado, en efecto,

${ }^{8}$ La expresión adecuaría, ampliándolo, el concepto de "mercado matrimonial" acuñado por Becker (1973), en línea con los trabajos de Ahuvia y Adelman, 1993; Hitsch, Hortacsu y Ariely, 2006. 
permite explorar algunas implicaciones del desarrollo de las relaciones románticas en la red, tales como la objetivación de las potenciales parejas y la mercantilización de uno mismo y de los demás como productos para la venta, la valoración, la compra o el descarte (Heino, Ellison y Gibbs, 2010), así como hablar de la mercantilización de la intimidad (Constable, 2009) o del afecto (Arvidsson, 2006).

\section{La búsqueda virtual de amor transnacional}

Diariamente millones de personas acceden a un ordenador y se conectan a Internet, ese microcosmos social internacional donde se crean comunidades virtuales, prosperan redes sociales, se realizan negocios, pueden cumplirse deseos y fantasías sexuales y encontrarse potenciales parejas (Wysocki, 1998).

La búsqueda de una pareja mixta por hombres españoles puede realizarse principalmente mediante las siguientes modalidades: conocimiento directo en España; portales de encuentros, chat y agencias matrimoniales a través de Internet; viajes; y presentación por "intermediarios casamenteros". Nosotros vamos a centrarnos aquí, únicamente, en las vinculadas a procesos de conocimiento transnacional cuyo soporte principal es la red, distinguiendo entre las búsquedas virtuales realizadas a través de redes o comunidades románticas y aquellas llevadas a cabo mediante agencias presentes en Internet.

\section{1. Redes románticas}

Cuando la búsqueda de pareja y, en muchos casos, la etapa de noviazgo posterior se ha realizado de forma autónoma en el ciberespacio, el acceso viene dado a través de portales especializados, chat, mensajería o programas de contactos.

Este procedimiento implica una serie de situaciones y fórmulas relacionales que se apartan del modelo de emparejamiento de tipo convencional, esto es, presentan particularidades específicas respecto de los encuentros cara a cara ${ }^{9}$. El espacio de sociabilidad es completamente distinto: el entorno cercano es substituido por el ciberespacio ${ }^{10} \mathrm{y}$ las estrategias de presentación del yo y del acercamiento mutuo deben adaptarse a este contexto de conocimiento a distancia, que tiene como característica fundamental el cambio de actividad presencial, es decir, la manera de "estar presente" en la vida del otro transforma la naturaleza de una de las parcelas esenciales de la relación, la de las citas. Como han señalado Chan y Cheng (2010: 306), la mayor diferencia entre la comunicación cara a cara y la mediada por ordenador se encuentra en la disponibilidad de señales del contexto social. En este sentido,

\footnotetext{
${ }^{9}$ En buena parte de la literatura anglosajona se utilizan los acrónimos CMC — computer-mediated Communications - y FtF - face-to-face - para distinguir las relaciones online de las offline. Para una comparación de ambas véase Chan y Cheng, 2010.

${ }^{10}$ El concepto de ciberespacio ha sido abordado por diversos autores como Gibson (2003) o Parreiras (2007), que exponen las circunstancias en que el ciberespacio permite que todo se procese en un mismo espacio al mismo tiempo y sin limitación alguna en la capacidad de locomoción del cuerpo. Gibson (2003) alude a la "euforia incorpórea del ciberespacio". Para algunos autores como Stephenson (1992) y Featherstone y Burrows (2000) en el ciberespacio se produce la creación de un cuerpo virtual, un cyberbody representado por el avatar — una representación gráfica dentro de la realidad virtual-, una figura que extrapola una concepción del cuerpo en cuanto a materia.
} 
ésta última se define por la falta de características espaciales, de apariencia personal y recursos de comunicación no verbal tales como la expresión facial, los gestos y posturas.

El proceso que se establece en las interacciones virtuales pasa por diversas fases: un primer momento de toma de contacto y conocimiento a través de los mensajes y la correspondencia telemática, donde la palabra adquiere una importancia capital, donde "hablan los dedos". En la modalidad de Chat no se adjunta perfil psicológico ni fotografía en primera instancia, siendo, pues, el discurso, el auténtico protagonista. De este modo, la palabra, desde el primer mensaje, adquiere una relevancia fundamental en los primeros encuentros de comunicación a distancia, ya que ejerce el poder de generar unas determinadas deducciones en el imaginario y propiciar la idealización:

Yo creo que empecé a conocerla ya desde su primer mensaje, le capté una cosa. La escritura, la gramática perfecta y saber expresarse ¿no? Entonces no sabía ni la edad, ni su estado. Entonces con esta persona capté enseguida y le mandé un mensaje a tal hora. Digo: si el mensaje está bien redactado, sin una falta de ortografía, todo correcto, ¿qué puede ser? Digo: una persona que tiene su trabajo, un horario, quizá de una profesión liberal, que tuviese por sus horarios la tarde libre, que tuviese una carrera, o unos estudios superiores... y entonces digo: Pues no es ninguna niña que quiera perder el tiempo. Y, sí, realmente fue. Yo me acerqué muchísimo, con su primer mensaje ya creo que me acerqué muchísimo (Julián, español, 50 años; Marisa, peruana, 39 años) ${ }^{11}$.

En los portales ya más elaborados — webs de citas - los usuarios pueden o deben incluir un perfil, con datos personales, exposición de lo que buscan, e incluso fotografías. Cuando dos personas empiezan su contacto en la distancia, una de las peticiones mutuas que suelen hacerse es, precisamente, el envío de fotografías que permitan poner "cuerpo", aunque sea "congelado", a los vericuetos de la imaginación. La distancia forma parte del delirio que posibilita la idealización, según nos refieren Beck y Beck-Gernsheim (1998: 338), pero las personas, llevadas por el referente que aún domina de las interacciones en directo, necesitan desde un principio ubicar sus pensamientos en una forma física concreta. Alguno de nuestros informantes nos ha comentado su reticencia o la de su pareja a desvirtuar mediante la presentación de su apariencia física, el buen entendimiento conseguido a través del lenguaje. Pero, cuando su confianza es mayor, acaban todos sucumbiendo y ofreciendo el material fotográfico solicitado aun a riesgo de que la imagen física pueda desagradar al otro o, por el contrario, en la confianza y certeza de que la seducción y el enamoramiento conseguidos sin el soporte de la imagen no van a derrumbarse por la aparición de ésta, puesto que la "herida romántica" ya fue hecha y no puede tener vuelta atrás.

${ }^{11}$ Cada cita o referencia a un/a informante especificará su nombre o pseudónimo, la nacionalidad, la edad y, si es el caso, el nombre o pseudónimo de su pareja, la nacionalidad y la edad. Cuando el/la informante no forme parte del colectivo de parejas mixtas, se indicará su nombre o pseudónimo, edad y referencia — profesión por ejemplo— que le vincula al tema. 
La presentación del perfil identitario autoconstruido y, al mismo tiempo, del perfil deseado, significa que el individuo debe concentrarse en la percepción propia ideal y la del otro, por lo que los lugares Web de citas agudizan nuestro sentido de singularidad (Illouz, 2007). A partir de ahí, a través de la mediación de los portales o programas de Internet, que facilitan una selección previa de perfiles compatibles, se establecen los primeros contactos con los candidatos o candidatas elegidos, de modo que el encuentro virtual se organiza bajo la égida de la ideología liberal de la elección y se inserta, asimismo, en la estructura de mercado. Heino, Ellison y Gibbs (2010) han explorado las maneras como la metáfora del mercado actúa entre los usuarios de estos portales y cómo influencia el modo en que se evalúan a sí mismos y a los demás e interviene en la toma de decisiones. Los sitios web de citas en línea, de este modo, representarían espacios, que evocan los del e-comercio, como Amazon.com por ejemplo, donde la gente va a comprar potenciales parejas románticas y a venderse a sí mismo con el deseo de encontrar una relación romántica exitosa. Arvidsson (2006), por su parte, utiliza la expresión de mercantilización del afecto para referirse a cómo los usuarios de estos portales participan en un proceso de construcción de sus perfiles para atraer a otros.

Tras la fase de tanteo inicial con todas las personas que se desee, se pasa a una segunda fase de la interacción telemática en la que la voz y la conversación visual en directo adquieren protagonismo. Se inaugura una comunicación más intensa con la persona que, a partir de los perfiles preseleccionados y los tanteos consiguientes, se adapta mejor a las opciones deseadas, con la satisfacción que proporciona no sólo el hecho de escoger, sino también el de ser escogido, puesto que Internet coloca a cada persona que busca a otra en un mercado abierto de competencia con los otros.

Este procedimiento invierte el orden de las interacciones románticas tradicionales, puesto que aquí el conocimiento precede a la atracción o a la presencia física y a la corporeización de las interacciones románticas convencionales (Illouz, 2007), si bien cabe matizar, a nuestro entender, el hecho de que la vertiente física no es obviada absolutamente puesto que, en el caso de Webs de citas, los perfiles son acompañados a menudo por fotografías que actúan como un reclamo de selección.

En esta segunda fase de intensificación comunicacional, las llamadas telefónicas - vía red clásica o a través de aplicaciones de Internet tales como el Messenger o Scape - representan un intento por materializar o, de alguna manera, corporeizar la relación. La conversación telefónica tiene una inmediatez parecida a la de la mensajería, pero aporta, además, un acercamiento superior, puesto que el proceso de estímulo-reacción es más rápido. También es más problemática, debido a esta misma rapidez, puesto que obliga a los miembros de la pareja a hablar sin la meditación o premeditación que se da a través del teclado del ordenador, en el que, además, es posible borrar y cambiar enunciados antes de enviar el mensaje. El hecho de utilizar el teléfono es asimismo muy útil, según los informantes, porque a menudo quien responde puede ser un miembro de la familia, con el cual también se entabla una conversación que puede favorecer el apoyo familiar. Han sido especialmente nuestras informantes mujeres las que nos han explicado que el hecho de que el novio hablara en ocasiones con los padres y se mostrara educado y respetuoso ha sido muy 
beneficioso para la valoración positiva que éste ha conseguido. El uso del teléfono va acompañado a menudo por la visualización más corporeizada que permiten los encuentros a través de una webcam.

Como usuarios exitosos que fueron o eran de estas modalidades, nuestros informantes nos explican, en general, las ventajas que tales interrelaciones telemáticas les han aportado: en primer lugar, la desinhibición, puesto que se sienten libres de los constreñimientos que impone la presencia directa, es decir, que se produce una especie de descorporeización que favorece la libre expresión verbal sin que se deba atender a los imperativos de la expresión no verbal. Como afirma Zanata (2007), en el ámbito virtual las conversaciones permiten acceder a un cierto grado de intimidad en menor tiempo que en el ámbito físico. Illouz (2007), por su parte, señala que el romance cibernético anula el cuerpo, cosa que permite una expresión más completa del yo auténtico. Jordi, un español de 41 años, casado con Sol, venezolana de 37 años, ilustra de manera diáfana tales presupuestos:

Y es curioso porque el e-mail es una forma de conocer a una persona bastante interesante. Cuando nosotros conocemos a alguien en la cafetería, en el trabajo, en la tienda, o en la barra de un bar, pues tenemos una serie de barreras físicas, de aspecto, nuestra forma de vestir, la distancia, el ruido, quién nos está mirando, la vergüenza... hay una serie de factores que condicionan la relación con esa persona a nivel de conocerse. Quiero conocer a esa persona, pero no me atrevo, qué dirán, pueden ocurrir mil cosas... o porque estoy en un ambiente laboral y no es apropiado que yo le pida nada a esta persona... es decir, que hay una serie de condicionantes. También el aspecto que puede engañar, personas que no te gusta su aspecto y luego hablas con ellas y te resultan más interesantes y viceversa... "ay, qué guapo y qué bien", pero pierde el interés de una forma espectacular. Claro, en el correo electrónico, hay una serie de barreras que las eliminas, vas directo adentro de esa persona y decirle: "soy así, soy asá, me gusta esto, me gusta lo otro" ... En una relación en que nos vemos cada fin de semana hablas poco de ti, hablas mucho de cosas, pero poco de ti. Y en el e-mail hablas mucho de ti y preguntas cosas concretas. No tienes vergüenza porque nadie te ve. Yo ahora, por ejemplo, a ti no te conozco apenas y estás sentada aquí, a un metro mío.... Es difícil que yo te pregunte: “¿qué tal van tus relaciones íntimas?” Es muy difícil ¿verdad que sí? Es casi imposible. Sin embargo, por e-mail es más fácil. Tú estás entrando a conocer a una persona a varios niveles, de una forma bastante directa y bastante rápida. ¿Por qué? Porque no necesitas tanto para... El factor vergüenza no existe porque esa persona que está, por ejemplo, en Bogotá ¿a mi qué más me da explicarle que yo con mi primera novia no sé qué? En cambio a ti no te voy a explicar qué hacía yo con mi primera novia... y ella hace lo mismo conmigo. Es diferente, es muy diferente la relación vis à vis, donde hay una serie de condicionantes que influyen, como nuestra educación, la vergüenza... que influyen a la hora de comportarnos y en lo que decimos. Lo que yo te diga a ti está muy condicionado por el grado de confianza que tengamos y esto en el correo electrónico no existe (Jordi, español, 41 años; Sol, venezolana, 37 años).

La desinhibición, como veremos, está íntimamente relacionada con el anonimato que preside las primeras interacciones. Ambas características permiten a su vez la posibilidad de profundización. Desde la propia casa —o a veces de los cibercafés, 
utilizados en bastantes ocasiones sobre todo por las mujeres en nuestro caso- los encuentros pueden ser incluso más asiduos que en una relación convencional, limitada a menudo a unos horarios o incluso a días concretos. Naturalmente, en nuestro caso, la comunicación transnacional debe tener en cuenta la diferencia de horarios entre los diversos países, pero es posible pasar muchas más horas "juntos", como nos cuentan nuestros protagonistas, a costa, incluso, de las horas de sueño de uno de ellos - sobre todo del hombre, por el hecho de que el final de la jornada laboral en los países latinoamericanos, la zona, como se dijo, de mayor afluencia de hombres españoles que buscan una novia transnacional ${ }^{12}$, coincide con la hora habitual de acostarse en España-. Por otra parte, la facilidad de la conexión y, asimismo, el relativo bajo coste del medio favorecen la asiduidad de los contactos y que el conocimiento mutuo pueda ser más profundo, puesto que la conciencia de la distancia física genera una necesidad de compensar la falta de la presencialidad física mediante la presencia emocional. La mayoría de testimonios inciden en presentar su caso como ejemplo del conocimiento más intenso que ha propiciado su implicación en la determinación de hablar diariamente, explicarse sus rutinas, sus problemas, satisfacciones, etc. En definitiva, pues, en las interacciones virtuales se suprimen los aspectos no gobernables del comportamiento expresivo del individuo y de este modo el control de las propias manifestaciones es mucho mayor que en la interacción cara a cara. La experiencia de Julián y de Marisa muestra de forma clara el conocimiento intenso y profundo propiciado por la relación virtual y, a su vez, como este medio resulta más apropiado, en distancias largas, para superar la coordenada del espacio, que no la del tiempo - dos categorías fundamentales de la experiencia y percepción humanas no inmutables y sujetas al cambio histórico-

Nos hemos pasado horas, cada día — en Internet—. Cada día dialogando, dialogando, horas, cada día. Ha sido tiempo, pero que nos ha dado fuerza, mucha fuerza, pero han sido dos horas, tres horas diariamente dialogando - en Internet-, entonces es una relación muy profunda... Y ahora esa costumbre de diálogo, estamos haciendo cualquier cosa y estaremos dialogando y estaremos hablando, a veces no vemos ni la televisión. La televisión está encendida y nosotros pues hablando. Fue un hábito que tomamos (Julián, español, 50 años; Marisa, peruana, 39 años).

Illouz (2007) hace una interesante reflexión sobre la diferencia entre la autopresentación del yo postmoderno, cuya flexibilidad implica una capacidad de ser sensible a diferentes contextos sociales y de representar papeles distintos en ellos, y la auto-presentación de las personas en los sitios Web de citas, que tiene un carácter opuesto, ya que implica un movimiento introspectivo hacia el interior del yo, es general y estandarizada, no es sensible al contexto, ni a la persona; su objetivo es presentarse uno mismo independientemente de la identidad de quien lea. Este trabajo de auto-presentación se aleja de la verdadera representación social y se realiza en

${ }^{12}$ En otro lugar (Roca et al., 2009) hemos profundizado en la geografía del deseo de los hombres españoles y sus razones y significados. Digamos sólo aquí que, en general, dichas geografías están íntimamente vinculadas a la economía política y a la lógica cultural del deseo, que en este caso concreto se sustentaría en el pasado colonial, el idioma y un sustrato cultural compartidos entre otros. 
términos lingüísticos y visuales - fotografías ${ }^{13}$ - no destinándose a otro específico, sino a un público generalizado y abstracto. Es evidente que estos sitios Web de citas pueden facilitar también la falsedad de las identidades, ya que es mucho más difícil la comprobación de rasgos que en una cita cara a cara, pero las personas objeto de estudio nos recalcan que se sirvieron de la sinceridad porque de este modo el resultado de la búsqueda podía ser mucho más "rentable" y eficaz ${ }^{14}$.

En suma, en estas modalidades telemáticas de conocimiento se daría una especie de paradoja entre realidad virtual y virtualidad real. Tal como señala Illouz (2007:186), Internet permite alcanzar algo sin precedentes: visualizar el mercado de parejas posibles. En el mundo real, en cambio, el mercado de parejas es virtual, ya que nunca se ve, sólo se presupone, es algo latente que se encuentra por ejemplo en discotecas, bares o cualquier zona frecuentada por gente que puede o no estar disponible y se requiere un esfuerzo mayor de acercamiento y seducción simplemente para comprobar si la persona es accesible o no. En la web, en cambio, el mercado es real y literal, no virtual: todos los usuarios están disponibles y buscando. Si la reflexión de Illouz resulta en buena medida certera, la forma franca y desinhibida con que nuestro informante Jordi expresa la misma idea resulta, más allá de una corroboración pertinente, una excelente muestra del valor y la luminosidad de la etnografía:

Yo al tiempo que la estaba conociendo a ella también conocí a gente por aquí, salía los fines de semana... Pero esa vía - Internet - me parecía más interesante, sinceramente... Tú una noche vas a una discoteca y, bueno, sí, conoces a dos o tres chicas, hablas con otras, te cruzas tres o cuatro palabras en cuatro horas que te estás allí tomándote unas copas. En cuatro horas en Internet... bueno... has podido visitar setenta perfiles, has escrito infinidad de e-mails... con una particularidad: te hablo como hombre, cuando tú ves a otra mujer en otro sitio, sea en el trabajo, sea en la discoteca o tal, yo no sé de buenas a primeras si esa persona busca pareja, si le apetece o no tener una relación, si ya la tiene... No sé a priori nada de ella y en consecuencia tengo que acertar, es decir, primero tengo que indagar para que después me diga si podemos quedar o me diga que no, aparte de que me guste... A lo

${ }^{13}$ Illouz (2007) apunta una de las características de este procedimiento telemático donde se entra en competencia con otros "buscadores": mientras que se intenta la originalidad lingüística, en el sentido de que el perfil psicológico resulte singular y así destaque de la masa homogénea, en cambio se da un convencionalismo o estandarización física, puesto que el perfil fotográfico es preferible que encaje en cánones establecidos de belleza y físico.

${ }^{14}$ Parreiras (2007) expone la diversidad existente en la creación de perfiles: El primero de ellos, Profile, sería el perfil oficial y verdadero. El segundo, Fake, aludiría a algo que es falso, falsificado, una especie de fingir lo que se es. En el programa Orkut, estudiado por la autora, el perfil Fake es aquél en el que se produce la creación de un personaje, de un discurso, de un nombre, de una historia de vida, en fin, de una nueva identidad. En el tercero, el perfil Mask, no se crea una nueva identidad, sino que normalmente se colocan características, preferencias y descripciones que no se expondrían en el perfil oficial. En los casos que nos ocupan todos nuestros informantes habrían recurrido a la construcción de un perfil oficial verdadero, puesto que el objetivo no es simplemente conocer gente y dialogar sino llegar a una relación de pareja y, por tanto, las falsedades acabarían descubriéndose en el cara a cara. Gibbs et al. (2010), no obstante, hallaron en su investigación el efecto negativo de la honestidad en el éxito de la empresa amorosa online, particularmente en el terreno de la auto-presentación. 
mejor de todas las mujeres que conoces solamente el 20\% buscan una relación. Sin embargo, en Internet son el 100\%; si no, no estarían allí; es decir, que encima tienes todo el trabajo hecho que es descartar a toda la gente que no quiere. De momento, sabes que todas quieren... Yo lo percibí como un sistema muy efectivo (Jordi, español, 41 años; Sol, venezolana, 37 años).

Debido al gran volumen de interacciones posibles, la ley del número tiene aquí una importancia crucial y parece haber cambiado de manera significativa las formas en que se desarrolla la vida romántica. Ahora en el ámbito de las relaciones románticas se debe tratar un volumen y una velocidad mucho más grandes de "producción", intercambio y consumo románticos. Es por ello, sin duda, por lo que Fiore y Donath (2004) proponen que estos portales pueden constituir algo así como el ejemplo ideal de un matrimonio mercantil, ya que ofrecen mucha mayor información sobre un amplio listado de parejas potenciales que la normalmente disponible en los encuentros cara a cara. Aun así, como nos revelan los testimonios de nuestros informantes, la novedad de este procedimiento y las posibles reticencias que aún puede generar hacen que la representación de los primeros encuentros se revista con fórmulas parecidas a las del encuentro cara a cara. A menudo se insiste en atribuir mucha importancia al azar, cuando se trata de un método donde la intencionalidad es patente, $\mathrm{y}$, por otra parte, se intenta incluso desestimar una de las características que hemos señalado como intrínsecas a tal procedimiento, la del gran volumen de interacciones posibles, es decir, muchos de nuestros protagonistas nos dicen que alguna razón de naturaleza circunstancial y puntual les llevó a utilizar Internet y que se produjo la afinidad precisamente con la primera persona con la que entablaron el contacto telemático. Laura - venezolana, 32 años-, que conoció a su actual esposo - Carlos, español, 36 años - a través de un Chat de Internet, o Aimée - cubana, 31 años - que conoció al suyo - Pedro, español, 31 años- por el mismo canal, así como otras y otros muchos informantes, son testimonios de cómo a menudo se presenta la circunstancia de acceder a conocer gente por Internet como producto no de una intención propia sino incentivado por amigos y conocidos. De esta manera se pretende presentar la situación con tintes de "flechazo" cibernético y destacar la singularidad de la pareja, así como enmarcar el encuentro casi con visos de predestinación. Este es el caso de nuestro informante Igor $^{15}$ y su pareja ucraniana Natalie, que era la primera vez que utilizaba el programa de contactos (ICQ) e Igor fue precisamente su primer interlocutor:

Bueno, cómo la conocí fue algo sorprendente, había tan pocas posibilidades de conocerla que ¡buf! si lo piensas de una forma lógica, no tendría sentido... Una vez un amigo mío me dio a conocer un programa llamado ICQ, muy conocido, estilo sms, con el cual podías escribirte con gente de todo el mundo y por aquel tiempo lo probé... Al principio no me centré en buscar nada ni nadie y hablaba con

${ }^{15}$ Queremos precisar que el contacto con este informante se realizó, precisamente, a través de Internet. Uno de los investigadores entró en un blog donde se discutía sobre el mundo eslavo y solicitó la colaboración de miembros de parejas mixtas. Igor respondió inmediatamente al requerimiento y se realizó la "entrevista" a través de mensajes electrónicos. 
gente de los más dispares lugares del mundo: China, Japón, Rusia... pero sin interés especial... Hablé con chicas de toda Rusia, pero también sin mucho interés, hasta que un día curiosamente cuando casi perdí el interés por este programa alguien me mandó un mensaje de Ucrania. Ella era Natalie. Natalie nunca usó este programa ni siquiera una vez; aquel primer día estaba con su amiga en un cibercafé aburriéndose y ese tiempo cogió un ordenador y se puso a hablar para matar el tiempo con gente española para practicar español, ya que ella estudió español (Igor, español, 26 años; Natalie, ucraniana, 24 años).

En este mismo sentido, existe un intento de desmarcarse, tomar distancia o no identificarse con la imagen de usuario compulsivo, necesitado, desesperado, de Internet. El "valor" normalizado en el mercado matrimonial sigue siendo aún el del conocimiento, del encuentro y de la cita cara a cara. La producción y la realización de esto en el espacio virtual aún no tiene el mismo valor - o lo anterior tiene valor añadido-.

Posiblemente, pues, nuestros informantes son conscientes de que Internet supone una clara instrumentalización de las interacciones, al otorgar un valor a las personas en un mercado estructurado, y un alejamiento de la tradición del amor romántico, donde predomina la espontaneidad frente al modo racional de escoger pareja o se presupone una separación de la esfera instrumental respecto de la de los sentimientos y el amado posee un carácter único y exclusivo, mientras que en Internet se trata con la abundancia, opciones infinitas, eficiencia, selección, etc. Y, conscientes de tales diferencias e inmersos todavía en una cultura de emparejamiento distinta, nuestros informantes de alguna manera se desmarcan de esa racionalización y nos presentan su encuentro cediendo aún un lugar privilegiado al espíritu característico del amor romántico tradicional. Parecería ser, pues, que tienen la necesidad de ubicar su relato en los cánones de la gran narrativa del amor romántico, un discurso que aborrece cualquier atisbo de interés y cálculo explícitos en la elección de pareja, a lo que se debe sumar, además, la crítica social encubierta.

El tercer paso, último, decisivo y culminante, de estas interacciones lo constituirá la cita en persona. En este punto uno de los dos, sobre todo el hombre, en nuestro caso, realiza un viaje al país de la mujer para conocerla de forma directa y comprobar si el conocimiento y sentimientos logrados a través de la expresión verbal son igualmente satisfactorios cuando se unen a la presencia física y la expresión no verbal. Este tipo de relaciones comienzan pues online y mudan, en algún momento, a offline $e^{16}$.

A partir de aquí la relación continúa durante un tiempo intercalando los tres tipos de recursos: correspondencia online, teléfono y viajes. Cabe decir que algunos de nuestros informantes realizaron este primer viaje de conocimiento en persona, directamente para casarse, es decir, que no hubo contactos personales intermedios, sino que se tomó la decisión de realizar la boda en el primero de los viajes que iba

${ }^{16}$ A diferencia de las relaciones románticas tradicionales que se iniciaban cara a cara $\mathrm{y}$, en bastante casos, en algún momento y por algún tiempo — servicio militar, razones laborales, emigración... - podían pasar a ser relaciones "postales". 
a poner en contacto directo a los "prometidos". Es el caso de Sonia y Javier. Su experiencia es una muestra paradigmática, además, de la sucesión de fases y la pluralidad de medios que van tejiendo la intensidad transnacional de estos noviazgos:

Yo me metí allí y hablamos y hubo... como que con él me quedé hablando y hubo bastante congeniamiento, conversar de cosas... Y así fue que lo encontré un día $\mathrm{X}$ sin pensarlo, no sé en qué canal entré y lo conozco a él. Y hablando me pidió el Messenger, que yo no daba a cualquiera, y le di y me dice: "¿que te viene bien tal día?”, y yo dije: "sí'. Y bueno, calculando: ¿cuántas horas hay de diferencia? Y entonces digo: voy a seguir. Y entonces: "mándame una foto...”, le mandé, pero nada de truquear, como soy, y ahí hablando, hablando. Y así.... Hasta que me dice: "Dame tu número de teléfono". Y me llamaba todos, todos los días... yo dije: “¡Este tío, digo, Dios mío!" Y no había ningún día que no me llamara. Sólo cuando me iba de viaje. Y en mi casa ya le tenían familiarizado, porque cuando no estaba, hablaba con mis padres. Y eso que él es tímido, yo no sé cómo..., no entiendo yo, tímido, tímido. Y de ahí lo peor viene... te sorprenderás, y seguimos, llamaba a mi casa, y luego flores, no sé como lo hacía; Interflora.... El día de no sé qué un ramo de flores. Mis padres se quedaban... ¿Y tú lo habias visto? Yo lo había visto en foto y en cámara, pero en vivo todavía no, nada. Y te parecía bien. Romántico.... No sé... De ahí mandaba fotos, mis padres los llamaba. Y cuando me iba de viaje les decía: "Ah, que se cuide mucho y... "; o sea, los enamoró a mis padres desde lejos. Y ellos allí: ¡Ay! Pasó ocho meses así hablando; o sea, fue una ilusión, una ilusión, como que sentías algo, una ilusión, ¿no? ¡Ay! pero como que estás ilusionada. Puedes estar haciendo mil cosas, pero estás ilusionada. Y eso es algo bonito que he logrado sentir. Bueno, pasó eso y me dice: “¿quieres casarte conmigo?” Y yo: "¡Qué me dices!" Le cambié de tema. Pasó una semana y me dice: “¿Ya lo has pensado?" Y le digo: "Es que..." Y al otro día me dice... Y le digo... no sé qué me entró, no sé, fue algo que no entiendo, y pensando y le digo que sí [se ríe] Y ahí pensando: ¡Oh, qué le he dicho que sí! ¡Oh! Y ya no... y me hacía mi cabeza... Y él me dice: "Prepara la boda y los papeles..." O sea ¿prepara la boda sin haberte visto? Nada. Y ¿sabes qué? El empezó a ver por el Internet, fue a un gestor aquí, no pagó nada, hizo todo el papeleo, que yo me quedé parada. Me decía: "mira, para la boda nos piden esto...". "Ah, bien, bien". Fue él quien me dijo para casarnos, noviembre fue cuando lo conocí, me dijo para casarnos en mayo. En mayo, sí. Había meses para... él hizo su pasaporte, se hizo papeles y me dice: "Tú sólo prepara la boda, el convite...” Y yo digo: “Mis padres, ahora!” [se ríe]. Digo: tengo que hablarles, pero, digo, a mi padre, cómo le voy a hablar y ya digo: mañana le diré. Y nada, que él había llamado y ya lo había arreglado y había pedido la mano por teléfono. Y llego yo a casa y mi padre... los dos los veo con una cara..., que se querían reír y al mismo tiempo... "Sonia, me dicen, que ha llamado el español”, le decían allá. "Mira, hija, yo, como he visto este chico lo que ha hecho, tantas cosas, también puede ser bueno, puede ser malo", me dicen mis padres, pero al hablar con él, al ver los detalles y mirado sus fotos de él y... incluso sus padres ya habían hablado con los míos, su madre más que todo para ver si... su familia también preocupada para ver dónde se iba su hijo, que nunca había salido de España. Ni siquiera aquí mismo, ni a Andorra... Me casé tres días después de haberlo visto... Tenía que poner todo lo que sabía de él en su cuerpo, en su cuerpo. Y yo decía: “¡Ah!, mira...” Y le veía cosas que era... Era todo lo que había parecido, o sea, cómo te puedo decir, no... 
no fue nada oculto, nada escondido. Todo, todo exacto (Sonia, peruana, 35 años; Javier, español, 37 años).

La culminación del proceso, en la mayoría de casos, consiste en la unión definitiva entre ambos que se produce mediante la migración por la mujer, que cambiará su residencia por la del compañero o esposo, esto es, el proceso de conocimiento finaliza con el hecho de convertirse, especialmente las mujeres, en "migrantes por amor"17.

Nos parece relevante destacar que por lo general la duración de estos noviazgos es bastante breve, de unos pocos meses. Sin duda, la velocidad e inmediatez de las interacciones que hemos comentado también favorece la rapidez de las decisiones $y$, por otra parte, el contacto directo entre los miembros de una pareja aún sigue considerándose el objetivo final e ideal, por lo cual las circunstancias de distancia que caracterizan la relación de estas parejas mixtas virtuales hacen que se tienda a buscar el acercamiento "real" con la mayor premura posible, además del patrón de casamiento en edad temprana en los países de origen de nuestras mujeres. En algunos casos se da un tiempo de "prueba" que lleve a la confirmación de las intenciones, pero en la gran mayoría la migración se planteará de forma definitiva.

\section{2. Agencias matrimoniales}

La otra opción, más elaborada y formalizada que la anterior, que también basa su itinerario de conocimiento a través de la red telemática, es el recurso a las agencias matrimoniales especializadas, más utilizadas y adecuadas en el caso de querer iniciar una relación con una mujer de la Europa del Este y, asimismo, la de ella con un hombre español. En este caso la búsqueda transnacional deliberada deviene más explícita, puesto que implica, por parte de ambos, una idea bien definida de lo que se quiere, un planteamiento más comprometido y al hombre le supone una inversión económica superior.

Para la descripción del proceso voy a centrarme en la propia experiencia de observación participante en una de estas agencias, incorporando, cuando así se precise, las posibles variantes existentes proporcionadas por la información obtenida del análisis de las páginas web de otras agencias y de las entrevistas que hemos realizado a agentes que trabajan en este negocio y a algunos informantes que las han utilizado.

El 24 de julio de 2006 realizamos una entrevista a Ernesto — pseudónimo-, soltero, de 37 años, ingeniero textil, responsable en España de la agencia noviasrusas. com - nombre ficticio-, inaugurada en 2003 después de que ya llevara funcionando unos años en Alemania y Estados Unidos. En abril de 2007 iniciamos los trámites para viajar, en junio, a Kiev a través de la agencia, que en este momento

${ }^{17}$ Acuñamos la expresión migrantes por amor en nuestro primer proyecto (ver nota 4), en 2006. En más de una ocasión hemos constatado la incomodidad que tal expresión produce, incluido el medio académico. Recientemente, no obstante, hemos comprobado que algunos autores han empezado a utilizarla, como por ejemplo Parrello, Guzmán y Buonanno (2010), que nos reconocen la autoría de la misma y la incorporan, en italiano, a su trabajo. 
contaba con cerca de 1.000 hombres españoles dados de alta y tenía 1.020 chicas publicitadas, con una o diversas fotos y su correspondiente perfil, mayoritariamente de $\mathrm{Kiev}^{18}$. No era necesario estar registrado para acceder al catálogo, en el que aparecían agrupadas por franjas de edad, siendo la de 25 a 30 años la más numerosa - con 300 mujeres ${ }^{19}$ - . El catálogo masculino no era accesible. Cada una de las mujeres incluidas en el catálogo contaba con una ficha en la que se aportaban los siguientes datos: fecha de nacimiento, estado civil, hijos, altura, peso, color de ojos y del cabello, ciudad de residencia, signo del zodíaco, empleo e idiomas y nivel de conocimiento - por ejemplo: "some English, need an interpreter"; "English, fluent French; Basic Italian"-, además de una breve descripción de unas cinco líneas en las que por lo general se describían las características destacables de su personalidad, la manera como era vista por los demás, sus sueños, hobbies, gustos y el tipo de hombre deseado o buscado. He aquí un ejemplo:

I'm purposeful, kind, accurate, active and romantic person. My main goal is to have strong family. I like to travel, to do sport and to drive car. At my free time I like to read and to meet my friends. I think that love is when you cannot live without your beloved person. I hope to meet faithful, decent, kind, sporty man (Vladislava, 23 años, manager).

Se incluía asimismo al menos una fotografía y en la mayoría de casos algunas más. Las mujeres no debían pagar dinero alguno por apuntarse a la agencia. Como ya observó Ara Wilson muy precozmente (1988), estos catálogos promueven, probablemente, una cosificación voyeurística de estas mujeres como "otras" en contraste con las feministas occidentales liberadas.

La presencia de estos catálogos en el proceso que estamos describiendo es uno de los elementos que ha generado más atención y consideración, muy posiblemente porque puede ser interpretado como una evidencia incontestable del carácter mercantil e instrumental que adquiere dicho proceso realizado a través de agencias especializadas. R. Halualani (1995: 45) señala que estos catálogos de mail-order brides representan un collage de discursos hegemónicos de carácter económico, sexual y racial que celebra la ideología dominante de signo capitalista anglo-patriarcal. K. Robinson (1996: 49), centrándose en catálogos de mujeres asiáticas, apunta que

${ }^{18}$ Durante nuestro breve trabajo de campo en Kiev contactamos con Natalie, directora de la agencia Natali, y nos explicó que el perfil de las 50 chicas inscritas en su agencia — de forma similar al que pudimos observar en la agencia noviasrusas.com - era el siguiente: el $60 \%$ tenía menos de 30 años, el 30\% contaba con hijos, el 30\% sabía alguna lengua extranjera — generalmente inglés—, el $85 \%$ disponía de estudios universitarios, y el $80 \%$ era de Kiev. Sus preferencias, a su vez, parecían claras y sencillas: hombres europeos, aunque algunas manifiestan no querer ir a Alemania, como pude comprobar en Kiev, en la entrevista que realicé, por ejemplo, a Elvira - 35 años, divorciada, con tres carreras universitarias: filología, intérprete y química - y otras no deseaban ir a EE.UU., porque pensaban que la personalidad de los hombres de allí es muy extraña.

${ }^{19}$ El resto de franjas de edad eran: menos de 25 años, de 31 a 35 años y más de 36 años. Por lo general, las mujeres inscritas no sobrepasaban los 50 años. En el caso de los hombres, por el contrario, los responsables de agencias nos informaron que la edad media era claramente superior a la de las mujeres, situándose entre 40 y 50 años y no siendo rara la presencia de hombres de más de 60 . 
tales productos constituyen lugares de fantasía para los hombres en una era en que sienten que los valores tradicionales de la preeminencia masculina en la familia ha sido minada. No vamos a poder entrar en al análisis de los contenidos de estos catá$\operatorname{logos^{20}}$, pero en cualquier caso queremos señalar, que siendo ciertas, estas afirmaciones anteriores no pueden separarse de la necesaria consideración de las voces de las y los protagonistas, cuya ausencia no deja de ser otra forma de estereotipo. Como ha señalado con acierto Wilson (1988), la mirada antropológica debe abordar las páginas de estos catálogos para encontrar a los hombres y mujeres que aparecen en ellos más allá de las representaciones. La etnografía, en este sentido, se desmarca de forma importante de los análisis basados única o principalmente en fuentes textuales. Nuestra experiencia nos muestra que la incorporación de estos extremos permite acceder a la variedad de aspiraciones, motivaciones y experiencias de las mujeres y los hombres envueltos en esas relaciones de correspondencia virtual, cuyas historias contrastan fuertemente con algunas ideas populares y académicas sobre ellas y ellos, así como constatar que en ellas ambos realizan elecciones, ejercen control, devienen, en suma, agentes activos en el proceso. Ello, por cierto, no quiere decir que no estén influenciados por ideologías de género, raza y nacionalidad y que sus acciones no estén limitadas por factores sociales, estructurales y culturales (Constable, 2003: 14-15).

En el caso de los hombres se les pedía que rellenaran un formulario de inscripción en el que debían hacer constar: nombre y apellidos, correo electrónico, teléfono, fecha de nacimiento, ciudad, provincia y país, el número de noches que deseaba pasar en Kiev - 3, 5, 7, ó 10 - las fechas aproximadas del viaje, una breve descripción personal, la lista de chicas - con el código que aparecía en el catálogo - que deseaba conocer y una foto. Existían dos modalidades de viaje: el de alto nivel y el VIP. La diferencia fundamental estribaba en que el último gozaba de "un catálogo de chicas específico", de asesoramiento sobre los perfiles adecuados para el cliente y de servicio de chofer en Kiev. En cuanto el precio, oscilaba entre los 1.300 euros para un viaje de tres días y los 1.900 para uno de 10 días en la modalidad más económica — de alto nivel—y entre los 2.100 y los 2.500 para la versión VIP. En ambos casos podían obtenerse descuentos por dos razones: unos 200 euros por realizar el viaje a Kiev con otras personas, y 400 euros si el cliente tramitaba y compraba directamente el billete de avión. El precio daba derecho a recepción y traslados al aeropuerto, alojamiento en un apartamento céntrico de la ciudad, asistencia durante la estancia y en la oficina de Kiev, contacto y presentación de las chicas previamente seleccionadas o seleccionadas en la misma oficina y servicio de traducción si era necesario. El proceso incorporado por esta agencia en aquel momento, que se mantiene aún en la actualidad sin cambios significativos, era como sigue: se recomendaba al cliente - hombre español, en este caso- que eligiera entre 15 y 20 chicas del catálogo. Sabemos, no obstante, por el responsable de la agencia y por lo que pudimos comprobar durante nuestro viaje y estancia, que

${ }^{20}$ Hemos presentado y analizado los contenidos de estos catálogos en otros lugares (Roca et al., 2009; Martínez, 2007). 
algunos hombres se resisten a ello y se limitan a elegir a una sola chica, a pesar de los consejos y advertencias de los responsables de la agencia en sentido contrario ${ }^{21}$, intentando alejarse de este modo de una lógica demasiado explícitamente mercantil y acercarse a otra más en sintonía con la narrativa del amor romántico. Una vez hecha la selección, la agencia dice que remite a las chicas seleccionadas el perfil del hombre que las ha elegido y el interés de éste en encontrarse con ellas en Kiev. La misma agencia asegura que normalmente entre el $80 \%$ y el $90 \%$ de las chicas acep$\tan$ la cita propuesta. Una vez la agencia ha recibido las respuestas de las posibles futuras novias, se lo comunica al cliente.

Como vemos, se trata de agencias dirigidas primariamente a los hombres de los "países ricos" que buscan mujeres en países de "menor desarrollo". De ahí que, por ejemplo, ellos paguen y las mujeres no lo hagan generalmente. Ellas, simplemente se registran, aportando su perfil y fotografías, del mismo modo que hace el hombre por su parte, que además debe abonar el pago de todos los costes del servicio. Por esto ellos pueden elegir y ellas sólo pueden elegir, generalmente también, aceptar o no la propuesta de su pretendiente. En ello los noviazgos vehiculados por este tipo de agencias reproducen los esquemas relacionales de género de tipo tradicional, con el hombre como protagonista y responsable de tomar la iniciativa y la mujer, en primera instancia, en un papel meramente pasivo (Roca, 1996: 166-177).

Habiendo ya elegido el cliente masculino y aceptado o rechazado cada una de las mujeres la invitación a un encuentro en su país con el hombre en cuestión, éste ya está en condiciones de realizar el viaje a Kiev. Se acuerda, pues, la fecha y el periodo de duración de la estancia. Una vez en destino, el cliente es recogido en el aeropuerto, junto al resto de hombres procedentes de España y de otros países que viajen por el mismo periodo, y trasladado a su apartamento. Nuestra estancia la realizamos del 16 al 26 de junio de 2007. Pudimos saber que durante este mes la agencia asistió a 39 personas procedentes de distintos países, entre ellos 6 españoles. El paso siguiente es la visita a la agencia, situada en una zona céntrica de Kiev, donde el cliente, de acuerdo con la asistenta que le ha sido asignada y que habla su idioma, programará los encuentros con las chicas seleccionadas durante los días en que vaya a permanecer en Kiev, a razón de unas 3-4 al día. Si durante la estancia el cliente quiere incrementar el número de encuentros, puede seleccionar más chicas ${ }^{22}$ a través del catálogo en la propia agencia. Este es el auténtico centro logístico y un lugar privilegiado de observación, puesto que es allí donde uno puede encontrarse con los hombres y mujeres que han acordado citas y con el personal de la agencia -intérpretes, administrativas, conductores, etc.- . Durante nuestra estancia coincidimos y pudimos dialogar, aunque con alguno con mayor facilidad que con otros, con tres hombres españoles: Juan, un canario de 46 años, divorciado, marcado por la muerte de su único hijo a los 20 años y promotor; Toribio, un médico salmantino

21 "El plan de actuación que yo ofrezco a la gente es: si vas a subir a Rusia o a Ucrania directamente a verte con una persona, es una locura, hazlo con varias, simplemente porque una foto puede quedar muy bien si el fotógrafo es un artistazo" (Juan, español, 51 años, responsable de agencia).

${ }^{22}$ Es habitual que algunas de las mujeres seleccionadas, una vez en Kiev, no estén disponibles, lo cual favorece la necesidad de realizar nuevas elecciones in situ. 
de 50 años; y Enrique, una ingeniero gallego de 50 años. Las presentaciones se realizan en la propia agencia. Posteriormente, la conversación puede desarrollarse en la misma agencia, que tiene habilitados unos pequeños salones al efecto, o trasladarse al exterior, paseando por la calle, visitando la ciudad o comiendo o cenando en algún restaurante, a cargo del cliente. Si la pareja no comparte ninguna lengua para comunicarse, la acompaña durante todo el encuentro una traductora ${ }^{23}$. La duración de estos encuentros, según pudimos constatar, variaba grandemente en función de las personas implicadas: desde 20 minutos - y un total de cerca de 20 chicas al día de un hombre norteamericano, que parecía realizar un auténtico casting de búsqueda de novia - hasta toda la jornada. En general, no obstante, los encuentros oscilaban entre la media hora y las dos horas. En teoría, se supone que el cliente masculino una vez encuentra a una mujer que le interesa, a lo largo de las presentaciones o al finalizarlas y hacer una valoración, solicitará quedar de nuevo con ella. Según nos comentó el responsable de la agencia, los casos de establecimiento de una relación de pareja en el primer viaje no son raros, aunque es más habitual para los hombres realizar más de una viaje para encontrar pareja. En algún caso aislado, no obstante, durante el primer viaje no sólo se llega a elegir novia, sino que incluso se regresa del viaje ya casado. En la mayoría de casos de "éxito matrimonial", el enlace acostumbra a realizarse en el país de origen de la mujer, por resultar más operativo:
Allí se van al registro civil con los papeles que se hacen aquí a los hombres, te casas, con los papeles te vas a la embajada de España, transcriben el matrimonio, les dan el libro de familia o según como les dan la tarjeta de residencia a la chica, todo depende de la persona que esté en ese momento en el Consulado. De riguroso nada, ni de serio tampoco. Depende de con quién te encuentras si te joden o no te joden (Juan, español, 51 años, responsable de agencia).

Teniendo en cuenta esta diversidad de factores — realización de más de un viaje, duración de la estancia, gastos no incluidos, etc. - junto con la tramitación de visados como consecuencia de la boda, puede afirmarse que el precio medio final puede oscilar entre 5.000 y 8.000 euros.

Una modalidad distinta, que ha ido desapareciendo en los últimos años, la constituyen las agencias que sólo venden perfiles y direcciones electrónicas a sus clientes. Al precio por cada contacto o listado de contactos, hay que añadir además el de la traducción del correo, si se precisa. Esta modalidad dio lugar a la aparición de la llamada táctica del hit and run, que consiste en vender un máximo de direcciones falsas en el mínimo tiempo, cerrar el portal de Internet, desaparecer por un tiempo y reabrir otro con un nombre distinto. Incluso en el caso que el planteamiento no se base deliberadamente en la estafa, esta modalidad es difícilmente eficaz:

${ }^{23}$ Este servicio, no obstante, como pudimos comprobar, únicamente se presta de forma algo excepcional en los casos en que la mujer sólo habla ruso/ucraniano. En muchas ocasiones, el conocimiento precario y chapucero por las chicas de alguna lengua de los países de procedencia de los clientes -inglés, francés, alemán, italiano, español...- es motivo suficiente para el ahorro del servicio de traducción. 
Hay agencias que sólo venden direcciones... Entonces te están vendiendo direcciones de chicas que se escriben con 40 personas en esa agencia y en la tuya 30 más. Hay gente de esa, que yo lo sé, que hay agencias que, claro, aquí cada persona te cuenta su historia: "Yo he comprado un paquete de 80 chicas, les escribí a todas, no me contestó ninguna". Claro, si les han escrito a cada una 30 ó 40 personas, y cada día a algunas, ¡cómo te van a contestar a ti! Ya es casualidad que una te conteste (Ernesto, español, 37 años, responsable de agencia).

En cualquier caso, lo cierto es que del cúmulo de "artículos" dedicados a explicar posibles fraudes y de las llamadas "guías anti-estafa", que las propias agencias incorporan en sus páginas web como prueba de su honestidad y transparencia, se puede obtener mucha información del funcionamiento de las agencias: las franquicias, las ventas de direcciones entre agencias, las bases de datos internacionales que alguna de ellas consigue - de incluso 100.000 candidatas - y, en fin, del monto de dinero que mueve este negocio que día a día aumenta su caudal de beneficios. Esta modalidad especialmente, aunque las agencias de catálogos vinculados a la realización de viajes también pueden usar parte de la estrategia, es la que ha dado lugar a la aparición del fenómeno de las denominadas scammers o "buscadoras de oro", las mujeres "falsas" que aparecen en los catálogos. Juan, responsable de una agencia, nos cuenta los pormenores del fraude:

¿Te cuento lo de las scammers? Funciona de la siguiente manera y yo muchas veces lo he pensado: si yo fuera mujer me iría a Moscú, y yo podría estar ganando $6.000 €$ al mes a costa de cuatro imbéciles. El planteamiento es de una elementalidad espantosa: este es el estereotipo de mujer...; o sea, si tuviéramos que montar una historia, conocemos a un fotógrafo y le decimos: "Oye, aquella chica es guapísima, véndeme unas cuantas fotos, que me hace ilusión para ponerlas en la mesita de noche”. El tío, como le das un dinero, me vende las fotos. Yo las escaneo y las pongo en mi página Web. Las pongo en agencia. El nombre tiene que ser real. Que hablas francés, ya tienes un mercado, que hablas inglés, ya tienes otro. Que hablas castellano, ya tienes tres. Yo conozco chicas que hablan hasta cinco idiomas en estos países... Y si no, a través de traductora. El planteamiento es: cuando la gente le empiece a escribir, le contesta: "Qué ilusión, qué contenta estoy de haberte conocido, cuándo vas a subir, cuándo voy a bajar". Y ya empieza: "Tengo un problema que no sé qué, que la abuela, que no sé cuánto y vamos justos de dinero”. Y ¿qué hace un caballero?: “¿Cuánto necesitas?” Claro, y luego el sueldo medio de la profunda Ucrania son de 50 a $100 €$ al mes, y eso aquí se lo gasta un español, un americano, un inglés, un alemán en un fin de semana un poco alocado. Imagínate qué esfuerzo puede hacer en mandarle a una chica, de la que está estúpidamente enamorado, todo ese dinero. Pues en el momento en que te encuentras con una serie de niñas con un poco de habilidad, ¿qué pueden sacar? No sé, seis, ocho o diez veces el sueldo medio de su país. A ver, cuando te encuentras una página Web que no te indica dirección, que no te indica teléfono, que no te indica nada, ¿qué puedes pensar? Te venden direcciones... Mira, hay una agencia en Barcelona que tiene página Web y te vende direcciones de un listado de 150 chicas por $50 €, 60 €$. Sale a 20 céntimos de euro cada dirección. Todas las chicas hablan castellano; o sea, concretar un tonto cada tres días, ya te sacas un sueldo. Historias de estas, cuidado que hay muchas (Juan, español, 51 años, responsable de agencia). 
Como dijimos, no obstante, en este negocio se tiende cada vez más a la rapidez y a la eficacia. El mismo Juan lo argumenta con su peculiar estilo discursivo:

Las chicas están cansadas, cansadas de recibir cartas, llamadas y correos electrónicos. Entonces, mucha gente compra por $3 €, 20 €, 7 €, 20$ céntimos de euro, una dirección y escribe, llama por teléfono, te puedo contar burradas... como llamar por teléfono de aquí a San Petersburgo para canturrearle a la chica aquello de "Bésame, bésame mucho...", o sea, burradas de esas te puedo contar un montón. Entonces las chicas lo que quieren es... no quieren cartas, no quieren fotos, no quieren promesas, quieren que venga el español. Y yo me estoy acostumbrando ya a decirle a la gente que eso de escribir cartas románticas y tal que lo olviden. Cartas operativas y oye: "Me gustan los perros, ¿te gustan sí o no?". "En mi casa ni fumo yo ni fuma el rey. ¿Fumas tú?”. Cosas como esas funcionan. Yo es lo que oriento a la gente y funciona (Juan, español, 51 años, responsable de agencia).

\section{Conclusiones}

La mayoría de las modalidades de búsqueda virtual de una relación romántica transnacional que hemos presentado evocan, tanto en la opinión pública como en un buen número de aportaciones académicas, el paso de una fórmula de noviazgo basada en la relación cara a cara con una pareja del propio entorno comunitario - conocida generalmente con antelación al establecimiento de la relación romántica y que se desarrolla a través del tiempo- a otra donde el crecimiento exponencial de posibles parejas desconocidas y esparcidas por el universo virtual y las formas de presentación, selección y contacto resultan especialmente susceptibles de ser abordadas bajo la retórica de la mercantilización, en un tipo de oposición, queremos hacer notar, del estilo de la clásica diferenciación de Tönnies — heredera a su vez de las postuladas por Maine y Durkheim - entre comunidad y asociación, entre relaciones personales y afectivas y relaciones instrumentales e impersonales. De ahí que la noción de mercantilización y su asociación a las relaciones de mercado pragmáticas e impersonales sea a menudo negada, mixtificada, mediatizada, transformada o disfrazada, generando una amplia variedad de discursos compensatorios que proclaman tanto la reciprocidad como el altruismo, las afirmaciones de amor como la autenticidad limitada (Constable, 2009: 58).

La noción de mercantilización permite iluminar, es cierto, las relaciones de poder inherentes a una variedad de relaciones íntimas, pero a su vez puede determinar en exceso una mirada exclusiva de tipo político-económico, enmascarando así la multiplicidad de las relaciones de poder y los aspectos potencialmente liberadores y transformadores de las subjetividades íntimas. En este sentido, pensamos que resulta oportuno señalar que la globalización no simplemente da lugar a una mayor mercantilización de la intimidad sexual y las relaciones maritales y reproductivas, sino que ofrece también oportunidades para definir nuevos tipos de relaciones y redefinir ámbitos, significados y expresiones de intimidad que pueden transformar y transgredir espacios y normas convencionales de género.

Tanto nuestras unidades de análisis como una de nuestras unidades de observación privilegiadas — el espacio virtual, la red— nos remiten también, según se 
insinuó ya, a la noción de comunidad y nos permiten revisarla creativamente. Se ha sugerido que las diferentes formas de relación online - redes sociales, chats, forum...- son una especie de comunidades de serie de B respecto a la comunidad tradicional, caracterizada por el cara a cara. Pero también se ha ido más allá, afirmándose por ejemplo que la contraposición entre comunidad virtual y territorial no tiene ninguna razón de ser, puesto que en el mundo contemporáneo todas las comunidades son, en cierto modo, virtuales, o que la comunidad online, incluso, parecería superar la vieja dicotomía entre comunidad y sociedad, puesto que están constituidas por lazos fuertes y débiles a la vez: los de los círculos donde todo el mundo se conoce, por una parte, y los que garantizan el éxito de la red y que permiten a los individuos salir al exterior (Aime y Cossetta, 2010).

De igual modo, las investigaciones recientes sobre el cambio de los patrones locales y globales y los procesos y las relaciones de intimidad están conectados a las viejas críticas de los modelos excesivamente binarios de lo público y lo privado, lo íntimo y lo impersonal, lo material y lo emocional, el amor y el dinero, lo local y lo global, la naturaleza y la cultura (Constable, 2009: 57). Dibujan perspectivas que están vinculadas a la amplia investigación etnográfica multisituada y transnacional que va más allá de la dicotomía local-global, situando las viejas asunciones sobre parentesco y relaciones sociales dentro de los contextos cada vez más globales, móviles y tecnológicamente mediados.

La etnografía, en este sentido, puede aportar una potente base empírica para superar las visiones generalmente presentes en el debate público y académico sobre las implicaciones, reducidas a una suerte de valoraciones positivas o negativas, que históricamente se producen ante la rápida introducción de cualquier innovación tecnológica e incluso ante el análisis del cambio social. Es en la etnografía, si se quiere, donde podemos ver el delicado balance de las tendencias utópicas y distópicas en el impacto de las TIC en la vida diaria de la gente. Las voces de los actores sociales nos han mostrado aparentes paradojas, certezas esperables y realidades polisémicas. Nos han mostrado, por ejemplo, que la ausencia de corporeidad comunicativa, del cara a cara físico, no tiene porqué rebajar ni la intensidad ni la calidad relacionales y que la mercantilización que chats, portales y agencias de Internet especializados en la búsqueda de pareja parecen promover y evidenciar, con catálogos a la carta, relaciones de competencia y elecciones que fácilmente tienden a la objetivación de los otros, también puede contrastarse con la capacidad de la comunicación mediada por ordenador para facilitar, en ocasiones, la desatención a los aspectos tangibles de la persona, como su imagen o su posición social, y la valoración de su personalidad, o la atenuación de las diferencias culturales. Como vemos, los juicios y conclusiones a los que podemos llegar dependerán en gran medida de la dimensión, entre las presentes, por ejemplo, en el concepto de comunidad, que privilegiemos y enfaticemos: la comunicativa o la centrada en el intercambio no instrumental con el otro.

Nuestra aportación, en fin, pensamos que contribuye a ubicar una parcela del amplio campo de las uniones mixtas, aquejado muy a menudo de la simplificación y el tópico, y de las relaciones virtuales, también sujetas mayoritariamente a la dicotomía del prejuicio sobre su bondad o maldad, en el incipiente terreno de complejidad 
que sugieren las distintas experiencias recogidas por diversos autores y por nosotros mismos, y a esbozar las unidades de análisis que resultan pertinentes y relevantes para abordar el análisis de estas parejas que incorporan elementos diversos de signo tradicional, de continuidad y cambio.

\section{Referencias bibliográficas}

AHUVIA, A. C.; ADELMAN, M. B.

1993 "Market metaphors for meeting mates". Research in Consumer Behavior, 6: 55-83.

AIME, Marco; COSSETTA, Anna

2010 Il dono al tempo di Internet. Torino: Giulio Einaudi editore.

ANDERSON, Benedict

1983 Imagined Communities. Reflections on the Origin and Spread of Nationalism. New York: Verso Press.

APPADURAI, Arjun

2001 La modernidad desbordada. Buenos Aires: FCE.

ARDÈVOL, Elisenda; et al.

2003 "Etnografía virtualizada: la observación participante y la entrevista semiestructurada en línea". Athenea Digital: Bellaterra. Disponible en: http://antalya.uab.es/ athenea/num3/ardevol.pdf.

ARVIDSSON, Adam

2006 “Quality singles': Internet dating and the work of fantasy". New Media \& Society, 8: 671-690.

BAKER, Andrea

2002 "What makes an online relationship successful? Clues from couples who met in cyberspace". Cyberpsychology and Behaviour, 5: 363:375.

2005 Double click: Romance and commitment among online couples. Cresskill: Hampton.

BARBARA, Augustin

1985 Marriages sans frontières. Paris: Les Centurión.

BECK, Ulrich; GIDDENS; Anthony; LASH, Scott

1994 Reflexive modernization. Politics, tradition and aesthetics in the modern social order. Stanford: Stanford University Press.

BECK, Ulrich; BECK-GERNSHEIM, Elizabeth

1998 El normal caos del amor. Barcelona: Roure.

BECKER, Gary

1973 “A theory of marriage: Part I". The Journal of Political Economy, 81: 813-846. 
BERMÚDEZ, Elba María

2007 Historias de unión y de amor en parejas mixtas que residen en la Comunidad Valenciana: relatos desde la masculinidad y la feminidad. Valencia: CeiMigra, Bancaja.

CAHILL, Demond

1990 Intermarriages in International Contexts: A Study of Filipina Women Married to Australian, Japanese, and Swiss Men. Quezon City: Scalabrini Research Center.

CHALVON-DEMERSAY, Sabine

1996 "Una societé elective. Scénarios pour un monde de relations choisies". Terrain 27: 81-99.

CHAN, Darius K. S.; CHENG, Grand H. L.

2010 "A comparison of offline and online friendship qualities at different stages of relationship development". Journal of Social and Personal Relationships, 21, 3: 305-320.

CHIN, Ko-lin

1994 "Out-of-Town Brides: International Marriage and Wife Abuse among Chines Immigrants". Journal of Comparative Family Studies, 25, 1: 53-71.

CLARK, Constance

2001 "Foreign Marriage 'Tradition' and the Politics of Border Crossings", en N. Chen et al. (eds.), China Urban: Ethnographies of Contemporary Culture. Durham: Duke University Press, 104-122.

COHEN, Erik

1986 "Lovelorn Farangs: The Correspondence between Foreign Men and Thai Girls". Anthropological Quarterly, 59, 3: 115-128.

CONSTABLE, Nicole (Ed.)

1998 Cross-Border Marriages: Gender and Mobility in Transnational Asia. Philadelphia: Pennsylvania University Press.

2003 Romance on a Global Stage. Berkeley: University of California Press.

2009 "The Commodification of Intimacy: Marriage, Sex, and Reproductive Labour". Annual Review of Anthropology, 38: 49-64.

COOKE, Fadzilah Majid

1986 Australian-Filipino Marriages in the 1980s. Queensland: Griffith University Press.

DELCROIX, Catherine GUYAUX, Anne

1992 Double mixte. París: L'Harmattan.

DONN, Jessica; SHERMAN, Richard

2002 "Attitudes and practices regarding the formation of romantic relationships on the Internet", Cyberpsychology and Behaviour, 5: 107-123. 
DORING, Nicola

2002 "'Studying online love and cyber romance", en B. Batinic, U.-D Reips y M. Bosnjak (eds.), Online social sciences, Seattle: Hogrefe and Huber, 333-356.

FEATHERSTONE, Mike (Ed.)

1990 Global Culture. Nationalism, Globalization and Modernity. London: Sage.

1991 Consumer Culture \& Postmodernism. London: Sage.

FEATHERSTONE, Mike; BURROWS, Rogers (Eds.)

2000 Cyberspace, Cyberbodies, Cuberpunk. London: Sage.

FIORE, Adrew T; DONATH, Judith S.

2004 "Online personals: An overwiew". CHI2004: 1395-1398.

GAMBURD, Michele Ruth

2000 The Kitchen Spoon's Handle: Transnationalism and Sri Lanks's Migrant Housemaids. Ithaca: Cornell University Press.

GARCÍA CANCLINI, Néstor

1995 Consumidores y ciudadanos. México: Grijalbo.

GIBSON, Willian

2003 Neuromancer. Sâo Paulo: Aleph.

GIBSS, Jennifer L.; ELLISON, Nicole B.; HEINO, Rebecca D.

2010 "Self-Presentation in Online Personals. The Role of Anticipated Future Interaction, Self-Disclosure, and Perceived Success in Internet Dating". Communication Research, 33, 2: 152-177.

GIDDENS, Anthony

2000 La transformación de la intimidad. Madrid: Cátedra.

GIL CALVO, Enrique

1997 El nuevo sexo débil. Madrid: Temas de Hoy.

HALUALANI, Rona Tamiko

1995 "The Intersecting Hegemonic Discourses of an Asian Mail-Order Bride Catalog: Pilipina 'Oriental Butterfly' Dolls for Sale”. Women's Studies in Communication, 118 (1): 45-64.

HANNERZ, Ulf

1998 Conexiones transnacionales. Madrid: Cátedra.

HARDEY, Michael

2002 "'Life beyond the screen: Embodiment and identity through the Internet". Sociological Review, 50: 570-585.

HEINO, Rebecca D.; ELLISON, Nicole B.; GIBBS, Jennifer L.

2010 "Relationshopping: Investigating the market metaphor in online dating". Journal of Social and Personal Relationships, 27, 4: 427-447. 
HINE, Christine

2004 Etnografía virtual. Barcelona: UOC.

HITSCH, Guenter J.; HORTACSU, Ali; ARIELY, Dan

2006 "What makes you click: Mate preferences and matching outcomes in online dating". MIT Sloan Research Paper, 4603-06, en http://ssrn.com/abstract=895442.

ILLOUZ, Eva

2007 Intimidades congeladas. Las emociones en el capitalismo. Madrid: Katz.

JACOBSON, David

1996 "Contexts and Cues in Cyberspace: The Pragmatics of Naming in Text-Based Virtual Realities”. Journal of Anthropological Research, 52: 461-479.

1999 "Impression Formation in Cybersapce: Online Expectations and Offline Experiences in Text-Based Virtual Communities". Journal of Computer-Mediated Communication, 5, 1. http://www.ascusc.org/jcmc/vol5/issue 1/jacobson. html\#VirtualCommunities.

JOHNSON, Ericka

2007 Dreaming of a Mail Order Husband: Russian-American Internet Romance. Durham: Duke University Press.

JOHNSON-HANKS, Jennifer

2007 "Women on the market: marriage, consumption, and the Internet in urban Cameroon". American Ethnologist, 34: 642-58.

MAC AN GHAILL, Mairtin (Ed.)

1996 Understanding Masculinities. Philadelphia: Open University Press.

MACINNES, John

1998 The End of Masculinity. Philadelphia: Open University Press.

MAINARDI, Giuditta

2006 Miroirs migratoires. Entre le Brésil et la Suisse: vécus de femmes brésiliennes. Bern: Peter Lang

MARCUS, Georges

1995 "Ethnography in/of the World System: The Emergence of Multi-Sited Ethnography”. Annual Review of Anthropology, 24: 95-117.

MARTÍNEZ, Lídia

2007 "Se busca esposa eslava/latina. El discurso de las agencias matrimoniales especializadas en mujeres del Este y de América Latina". Actas del V Congreso sobre la Inmigración en España. Migraciones y desarrollo humano. Valencia. Disponible en: http://www.adeit.uv.es/inmigracion2007/index.php.

MAYANS, Joan

2002 Género Chat o cómo la etnografía puso un pie en el ciberespacio. Barcelona: Gedisa. 
MELO, Renata de

2000 "Vivendo um Conto de Fadas: O imaginário de gênero entre cariocas e estrangeiros", en M. GOLDENBERG (org.), Os Novos Desejos. Rio de Janeiro: Record, 147-183.

MILLER, Daniel; SLATER, Don

2000 The Internet: An Ethnographic Approach. New York: Berg.

ORDÓÑEZ, Raquel

1997 “Mail-Order Brides: An Emerging Community”, en M. P. Root. (ed.), Filipino Americans: Transformation and Identity. Thousand Oaks: Sage Publications, 121-142.

PARREIRAS, Carlos

2007 "Sexualidades.com: uma análise das relaçöes interperssoals em comunidades virtuals". $31^{\circ}$ Encontro Anual da ANPOCS, Caxambu.

PARRELLO, Santa; GUZMÁN, Maricela Osorio; BUONANNO, Giuliana

2010 "Migranti per amore. Rinunce, risorse e oportunita nell'espatrio femminile dal Messico all'Italia". Rivista di Studi Familiari, 1: 5-24.

PARREÑAS, Rachel

2005 Children of Global Migration: Transnational Families and Gendered Woes. Stanford: Stanford University Press.

PIPER, Nicola; ROCES, Mina (Eds.)

2003 Wife or Worker? Asian Women and Migration. New York: Rowman \& Littlefield.

RHEINGOLD, Howard

1996 La comunidad virtual: una sociedad sin fronteras. Barcelona: Gedisa.

RIAÑO, Yvonne

2003 "Migration of Skilled Latin American Women to Switzerland and Their Struggle for Integration", en Y. Mutuso (ed.), Latin American Emigration: Interregional Comparison among North America, Europe and Japan. Osaka: JCAS, National Museum of Ethnology.

RIAÑO, Yvonne; BAGHDADI, Nicolas

2007 "Je pensais que je pourrais avoir une relation plus égalitaire avec un Européen'. Le rôle du genre et de l'imaginaire géographique dans la migration des femmes". Nouvelles Questions Féministes, 26, 1: 38-53.

ROBERTSON, Roland

1992 Globalization, Social Theory and Global Culture. London: Sage.

ROBINSON, Kathryn

1996 “Of Mail-Order Brides and 'Boys Own' Tales: Representations of Asian-Australian Marriages”. Feminist Review, 52: 53-68. 
ROCA, Jordi

1996 De la pureza a la maternidad. Madrid: Ministerio de Educación y Cultura.

2009 "Migraciones amorosas. Migraciones (re)negadas". Revista Migraciones, 25: 89-124.

ROCA, Jordi ; et al. (Coords.).

2009 Amor importado, migrantes por amor: la constitución de parejas entre españoles y mujeres de América Latina y de Europa del este en el marco de la transformación actual del sistema de género en España. En: http://www.inmujer.migualdad.es/ mujer/mujeres/estud_inves/766.pdf.

RODRÍGUEZ, Dan

2007 "Inmigración y modelos de incorporación: contextos, claves del debate y tendencias de futuro". Documentos CIDOB. Migraciones, 12. Barcelona: Fundació CIDOB.

SCHOLES, Robert

1999 "The Mail Order Bride Industry and Its Impact on Immigration". International Matchmaking Organizations: A Report to Congress (Appendix A). En: http://www. ins.usdoj.gov/graphics/aboutins/repsstudies.Mobrept_full.pdf.

SEIDLER, Victor. J.

2006 Masculinidades. Culturas globales y vidas íntimas. Barcelona: Montesinos.

SHUMWAY, David R.

2003 Modern Love: Romance, Intimacy and the Marriage Crisis. New York: New York University Press.

SIMONS, Lisa A.

1999 "Mail Order Brides: The Legal Framework and Possibilities for Change", en G.A. Kelson, y D. Delaet (eds.), Gender and Immigration: 127-143. New York: New York University Press.

STEPHENSON, Neal

1992 Snow Crash. New York: Bantam.

SUZUKI, Nobue

2003 Battlefields of Affection: Gender, Global Desires and the Politics of Intimacy in Filpina-Japanese Transnational Marriages. Tesis Doctoral. Dept. Anthropology. University of Hawaii: Manoa.

THAI, Hung Cam

2008 For Better or Worse: Vietnamese International Marriage in the New Global Economy. New Brusnwick: Rutgers University Press.

WANG, Hong-zen; CHANG, Shu-ming

2002 "The commodification of international marriages: cross-border marriage business between Taiwan and Viet Nam". International Migrations, 40: 93-116. 
WILSON, Ara

1988 "American Catalogues of American Brides", en J. Cole (ed.), Anthropology for the Nineties. New York: Free Press, 114-125.

WYSOCKI, Diane Kholos

1998 "Let your fingers do the talking: Sex on an adult chat-line". Sexualities, 1: 425-452.

ZANATA, Mariana

2007 "Orkut e blogs: O público, o privado e o íntimo na era da sociedade em rede". Universidade de Sâo Paulo. Mimeografiado.

ZELIZER, Viviana A.

2005 The Purchase of intimacy. Princeton: Princeton University Press. 